\title{
EDUCAÇÃO DE TEMPO INTEGRAL EM SANTARÉM: AÇÕES DA SECRETARIA MUNICIPAL DE EDUCAÇÃO
}

\author{
FULL-TIME EDUCATION IN SANTARÉM: \\ ACTIONS OF THE SECRETARY OF EDUCATION
}

\section{EDUCACIÓN A TIEMPO COMPLETO EN SANTARÉM: ACCIONES DE LA SECRETARIA MUNICIPAL DE EDUCAÇÃO}

Gerusa Vidal Ferreira ${ }^{\mathrm{I}}$

Maria Lília Imbiriba Sousa Colares ${ }^{\mathrm{II}}$

'Universidade Federal do Oeste do Pará, Pará - Brasil. E-mail: gerusavidalster@gmail.com

IIUniversidade Federal do Oeste do Pará, Pará - Brasil. E-mail: lilia.colares@hotmail.com

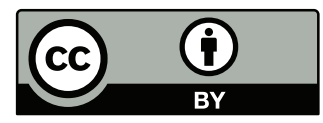

Educação: Teoria e Prática, Rio Claro, SP, Brasil - eISSN: 1981-8106

Está licenciada sob Licença Creative Common

\section{Resumo}

O tempo integral e a ampliação dos espaços escolares são temas recorrentes nos debates educacionais. Este artigo descreve as ações que a Secretaria Municipal de Educação de Santarém (Semed) desenvolveu no período de 2008 a 2014 para a implementação da educação de tempo integral. A pesquisa teve por base uma dissertação de mestrado desenvolvida no PPGE/UFOPA e foi feita por meio de pesquisa bibliográfica e documental, com abordagem qualitativa. Para a fundamentação e as análises recorreu-se a estudiosos do tema, à legislação e a outros 
documentos, tais como os Cadernos da Série Mais Educação do Ministério da Educação. Os resultados demonstram que a secretaria instituiu algumas ações de ampliação da jornada escolar, como a oferta de educação escolar integral em uma escola do campo e em uma na zona urbana, além do atendimento complementar em outras duas escolas diferenciadas e a implementação do Programa Mais Educação em dezoito escolas, a qual foi objeto de maior atenção neste estudo. O currículo se configurou pela ampliação dos conteúdos e do tempo, sem que estes se integrassem com as atividades regulamentadas pela escola, evidenciando a dicotomia entre turno e contraturno, aprendizagem e diversão, conhecimento científico e conteúdos éticos e estéticos.

Palavras-chave: Educação. Tempo Integral. Currículo.

\section{Abstract}

Full-time education and the expansion of school spaces are recurring themes in educational debates. This article describes the actions the Secretary of Education of Santarém (SEMED) developed from 2008 to 2014 to implement full-time education. The research builds on a master's degree dissertation developed in the PPGE/UFOPA, and on bibliographical and documental research, with a qualitative approach. For theoretical foundation and analysis, we resorted to researchers that are involved with the theme, legislation, and other documents, such as the notebooks of the Mais Educação program from the Ministry of Education. The results show that the Secretary created actions to expand school day, for example, by offering full-time education on a country school and on an urban school, in addition to a complementary care in two other schools and implementation of the Mais Educação program in eighteen schools, which was the main object of this study. The curriculum comprise the expansion of content and time, without integration with the activities regulated by the school, demonstrating the dichotomy between shift and counter-shift, learning and fun, scientific knowledge and ethical and aesthetic content. Keywords: Education. Full-Time Education. Curriculum.

\section{Resumen}

El tiempo integral y la ampliación de los espacios escolares son temas recurrentes en debates educativos. El artículo describe las acciones que la Secretaría Municipal de Educación de Santarém - SEMED desarrolló en el periodo entre 2008 y 2014 para la implementación de la educación a tiempo completo. Se basó en una tesis de maestría desarrollada en PPGE/UFOPA, 
mediante investigación bibliográfica y documental, con abordaje cualitativo. Para fundamentación y análisis, se recurrió a los estudiosos del tema, a la legislación y a otros documentos, como los Cuadernos de la Serie Mais Educação del Ministerio de Educación Brasileño (2009). Los resultados demuestran que la secretaría instituyó algunas acciones de ampliación de la jornada escolar. Como, por ejemplo, la oferta de educación escolar de tiempo completo en una escuela del campo, y una de la ciudad, además de la atención complementaria en otras dos escuelas diferenciadas y el Programa Mais Educação en dieciocho escuelas, que fue objeto de mayor atención en este estudio. El currículo se configuró en la ampliación de contenidos y del tiempo, sin su integración con las actividades reguladas por la escuela, evidenciando la dicotomía entre turno y contra-turno, aprendizaje y diversión, conocimiento científico y contenidos éticos y estéticos.

Palabras clave: Educación. A tiempo completo. Currículo.

\section{INTRODUÇÃO}

O presente estudo é um recorte dos resultados da pesquisa de mestrado do Programa de Pós-graduação em Educação da Universidade Federal do Oeste do Pará(PPGE/UFOPA), linha de pesquisa "História, Política e Gestão Educacional na Amazônia” e que objetivou apresentar as ações que a Secretaria Municipal de Educação (Semed) de Santarém desenvolveu para a adequação do currículo escolar, na perspectiva de atender a legislação referente a educação integral, no período de 2008 a 2014. Constatou-se que, incialmente, a Semed ofertou a educação escolar integral em uma escola do campo, e uma na zona urbana, além do atendimento complementar em outras duas escolas e o Programa Mais Educação em dezoito escolas

Para o alcance do objetivo proposto utilizou-se a técnica da análise bibliográfica e documental, cujas fontes foram: relatórios da Semed, Projetos Políticos Pedagógicos (PPP) das escolas e da secretaria, portarias, decretos e leis municipais, federais, os Cadernos da Série Mais Educação do Ministério da Educação (2009) e os documentos legais que tratam sobre o Programa mais educação.

A ampliação do tempo escolar constitui realidade em muitas escolas públicas brasileiras, apontando para a consolidação da educação de tempo integral como política pública. No município de Santarém, as ações de educação de tempo integral vêm sendo implementadas pela Secretaria de educação, por meio dos programas, projetos e escolas de tempo integral. Nesse sentido, apresentamos neste artigo os aspectos conceituais da educação integral e de tempo integral e as ações da Semed para Ampliação do Tempo Escolar no município de Santarém. 
Como será demonstrado ao longo do artigo, a ação mais visível da Semed se deu por meio do Programa Mais Educação. Em 2009, ano de sua implantação, atingiu 18 das 409 escolas sob a responsabilidade da rede municipal. Em 2014, ano final de coleta de dados para a realização deste estudo, já atingia 215 escolas, saltando o atendimento inicial em 2009 de 2.412 alunos para 19.596. Eis a razão do estudo ter se centrado com mais intensidade na busca de compreensão do PME desenvolvido na Secretaria Municipal de Educação de Santarém, visto sob a perspectiva de uma política indutora do MEC para a educação de tempo integral.

\section{EDUCAÇÃO INTEGRAL E DE TEMPO INTEGRAL: ASPECTOS CONCEITUAIS}

Por educação integral compreende-se a formação que considera o ser humano como ser multifacetado. Essa concepção pressupõe o resgate, na filosofia, das dimensões humanas: a ética, a estética e a episteme. Assim, para educar, há que se conjugar o tempo e o modelo de educação, considerando uma formação que oportunize o desenvolvimento da faculdade de compreender o mundo por meio dos sentidos (estética). É necessário, também, incluir atividades que abordem a ética - entendida como ciência da conduta humana - no que concerne aos valores e à maneira de pensar, cooperar, consumir e se solidarizar com o outro semelhante, com os animais, rios, mares, florestas. O desenvolvimento cognitivo, a episteme, não deve ser negligenciado, mas também não deve haver supervalorização em detrimento das outras dimensões (PAVIANI, 2008).

Os espaços educativos devem oportunizar o acesso diversificado ao conhecimento que possibilite a evolução não só do raciocínio, do pensamento, da memória, mas também da imaginação, da afetividade, da empatia, dos esportes e do lazer. Esses aprendizados são mediatizados pelas relações humanas, o que necessariamente pressupõe a necessidade da ética. Ao se relacionar, os seres humanos imprimem juízos de valor, neste processo exercita-se a moral, elemento fundamental da vida humana. Subsidiando esse raciocínio. Goergen acrescenta que:

\footnotetext{
A educação moral pode ser entendida como um dos aspectos da educação integral, que abrange a educação corporal, a educação intelectual, a educação afetiva, a educação artística, para ficarmos apenas nos aspectos mais tradicionais. A educação ocupa um lugar de destaque porque pretende dar uma orientação e um sentido ao ser humano como um todo; ela, de certo modo, perpassa transversalmente todas as dimensões da formação humana (GOERGEN, 2005, p. 1006).
}

Pensar no tempo integral nas escolas incide levar em consideração as variáveis: tempo, espaço e oportunidades de aprendizados, essas variáveis não são neutras, assim como qualquer 
ato educativo é intencional. Quando as iniciativas educacionais se limitam a ampliar o tempo escolar em função do assistencialismo, apenas para suprir as carências, sejam elas, sociais ou financeiras de alguns indivíduos, sem ofertar-lhes a formação ética, estética e intelectual, oportunizar-se-á, apenas mais tempo do mesmo tempo, perpetuando a visão fragmentada da realidade sem compromissos reais com a formação emancipadora.

$\mathrm{Na}$ educação concebida como integral busca-se ampliar as capacidades intelectuais, físicas, com o intuito de desenvolver a autonomia intelectual, moral, dos educandos. Assim, o papel da escola é oferecer a "cultura geral, humanista, formativa, que equilibre de modo justo o desenvolvimento da capacidade de trabalhar manualmente (tecnicamente, industrialmente) e o desenvolvimento das capacidades de trabalho intelectual". (GRAMSCI, 2001, p. 33).

Enfim, educação integral pressupõe ver o educando como um todo. $\mathrm{O}$ espírito não é considerado do ponto de vista puramente intelectual, formal ou de conteúdo, mas, sim, em relação com as suas condições sociais. (JAEGER, 1995). Para isso, é preciso uma reformulação da escola e da educação que se tem para não reduzi-la ao mero assistencialismo ou ao cumprimento vazio dos dispositivos legais.

\section{AÇÕES DA SEMED PARA AMPLIAÇÃO DO TEMPO ESCOLAR EM SANTARÉM}

A Semed é responsável por gerenciar a educação pública do município de SantarémPará. Em 2014, atendeu 59.954 alunos em seus diferentes níveis e modalidades, distribuídos em 409 unidades escolares, sendo 10.369 alunos matriculados nas unidades municipais de Educação Infantil e Pré-Escola, 3.677 na Educação de Jovens e Adultos - EJA, 400 no Projovem, 66 no Programa Brasil Alfabetizado e 45.442 no Ensino Fundamental. Do total dos alunos matriculados, 2.307 são indígenas e 812 são quilombolas (SANTARÉM, 2015a).

TabelaI - Demonstrativo dos números de matrículas na rede municipal de ensino - 2014

\begin{tabular}{lcc}
\hline \multicolumn{1}{c}{ REGIÃO } & $\mathbf{N}^{\mathbf{0}}$ DE ESCOLAS & $\mathbf{N}^{\mathbf{0}}$ DE ALUNOS \\
\hline Urbana & 58 & 30.731 \\
UMEIs Cidade & 26 & 3.174 \\
Campo - Planalto & 87 & 9.269 \\
Campo - Rios & 236 & 16.651 \\
UMEIs Planalto & 2 & 129 \\
TOTAL GERAL & $\mathbf{4 0 9}$ & $\mathbf{5 9 . 9 5 4}$ \\
\hline
\end{tabular}

Fonte: Santarém, 2015c 
As ações da secretaria para ampliação da jornada e dos espaços escolares foram surgindo paulatinamente, como a Escola da Floresta (2008) e a Escola do Parque (2010), voltadas para a educação ambiental e a valorização da cultura local. A Escola de Arte (2014), com ênfase na iniciação artística. E a adesão do Programa Mais Educação (2009), principal política indutora da ampliação da jornada escolar do Brasil.

\subsection{Escola de atendimento complementar}

A Escola da Floresta (2008) e a Escola do Parque (2010) foram pensadas para desenvolver a educação ambiental, constituindo-se, as primeiras iniciativas de ampliação do tempo escolar pela Semed e valorização da cultura local, por meio de um espaço de compartilhamento em áreas de preservação ambiental.

A Escola da Floresta, localizada em uma área de proteção ambiental, Km 26 da Rodovia Everaldo Martins, na comunidade de Caranazal, próxima ao distrito de Alter do Chão, possui uma área de 33 hectares de floresta (floresta secundária). Atende, prioritariamente, a alunos do sexto ao nono ano. Também atende a estudantes de outras redes de ensino (públicas e privadas).

Nesse espaço, a sala de aula seria a própria floresta. O atendimento dos alunos até o ano de 2012 era de 7 horas diárias. A partir de 2013, apesar de a escola continuar funcionando no horário matutino e vespertino o atendimento aos alunos foi reduzido a 4 horas diárias.

A Escola do Parque localiza-se dentro do Parque da Cidade, área verde urbana. Atende aos alunos do primeiro ao quinto ano do ensino fundamental e tem, como ênfase, educação ambiental, contribuindo para a formação integral. O atendimento da Escola do Parque também era de 7 horas diárias, tempo que foi reduzido, a partir de 2014, a um turno.

É possível perceber no projeto pedagógico e nos relatórios das duas escolas a preocupação com o atendimento dos alunos da rede e, concomitante a isso, com a formação de docentes para utilizar os temas ambientais transversalmente nas escolas da rede municipal. Essa intenção está descrita nos objetivos da proposta pedagógica das duas escolas:

Objetivo Geral: Proporcionar mudanças de práticas e valores quanto à preservação e conservação do meio ambiente, através de um espaço de compartilhamento de experiências e ações em educação ambiental junto à comunidade escolar municipal e sociedade civil organizada. (SANTARÉM, 2014b, p. 3) 
Objetivo Geral: Sensibilizar a comunidade escolar e sociedade civil organizada por meio de atividades pedagógicas em Educação Ambiental, incentivando-os a mudanças de postura e valores quanto à preservação e conservação do meio ambiente. (SANTARÉM, 2014b, p. 5)

A metodologia de trabalho da Escola do Parque e da Escola da Floresta se assemelha, ou seja, o atendimento por turmas, em média cada uma com 35 alunos. De acordo com o projeto pedagógico da escola, o ensino é pautado em princípios metodológicos inspirados na proposta de Educação Popular de Paulo Freire. A escola conta com uma equipe multidisciplinar composta por pedagogos, licenciados em Letras e Artes, biólogos, gestores ambientais e educadores alimentares. $\mathrm{O}$ atendimento aos alunos pela Escola da Floresta e Escola do Parque é realizado mediante uma agenda anual, definida no início do ano, na semana de planejamento pedagógico das escolas da rede municipal.

A Escola Municipal de Arte "Professor Emir Hermes Bemerguy" está situada na rua Hortência S/N, bairro Jardim Santarém. Foi inaugurada em 20 de junho de 2014, tendo por finalidade oportunizar e estimular o conhecimento das linguagens artísticas: da música, da dança, do teatro e artes plásticas para valorização da cultura na formação do cidadão. A rotina da escola se organiza por meio da oferta de oficinas, no período de três meses para cada uma, encerrando com uma mostra dos resultados à comunidade.

Em seu plano de ação, a escola apresenta objetivos claros, voltados para a iniciação artística em várias áreas como música, artes plásticas, teatro entre outras. Essas atividades são ofertadas por meio de oficinas. A escola atende, prioritariamente, às crianças da rede municipal de ensino. Entretanto, por ser recente sua atuação, possui poucos registros, sendo arriscado esboçar uma análise mais detalhada da mesma.

\subsection{As escolas de tempo integral}

As outras iniciativas de ampliação do tempo escolar, em Santarém, se concretizam com as Escolas de Ensino Fundamental Frei Fabiano Merz e Irmã Dorothy Mae Stang, construídas em 2011 e 2012, sendo, respectivamente, uma escola de tempo integral da cidade e do campo. As duas iniciativas trabalham a educação em tempo integral e promovem atividades dentro e fora da escola.

A Escola Frei Fabiano Merz, localizada na Avenida Paulo Maranhão, no bairro do Caranazal, é reconhecida pelo MEC como instituição de ensino em tempo integral, como pode 
ser constatado no site do MEC/Inep. Foi a primeira escola de tempo integral do município. Seu horário de funcionamento é das 7 h30 às 16 h30.

A escola de tempo integral pressupõe uma concepção de educação que engloba todas as dimensões formativas do sujeito e que este tem direito a essa educação plena. Obviamente, esse projeto de formação necessita de um padrão arquitetônico diferenciado e de mais tempo de formação; não cabe, portanto, numa escola de quatro horas diárias, nem nos espaços reduzidos desse modelo de escola existente. As ações educativas, na perspectiva multicultural, demandam tempo e investimento no capital cultural, nas pessoas e nos processos, construindo-se as relações entre a cultura e o saber escolar.

A Escola Irmã Dorothy Mae Stang, situada na Rodovia Estadual Dr. Everaldo de Sousa Martins, km 24 s/n na comunidade de Caranazal, região do Eixo Forte de Santarém foi inaugurada no ano de 2012, e seu Projeto Político Pedagógico, construído recentemente, foi submetido ao Conselho Municipal de Educação (CME) para avaliação e composição do processo de autorização da escola. Recebe crianças do sexto e sétimo ano. Também é pioneira em Santarém, sendo a única escola de ensino regular de tempo integral do campo.

Segundo a literatura utilizada, o bom desempenho da escola de tempo integral está associado à articulação entre os diferentes saberes, entre o conhecimento formal e os saberes comunitários, entre escola e sociedade, na superação do turno e contraturno, instituindo uma grade única. O diálogo, como base de atuação pedagógica, agrega experiências para a escola de tempo integral e para a comunidade, por meio das relações que se complementam, embora, nem sempre, sem conflitos. Estes são até necessários à vivência democrática em que, de um lado, os alunos se beneficiam, ampliando suas potencialidades, de outro, a escola reconhece e valoriza suas culturas, dando visibilidade às mesmas.

\subsection{O Programa Mais Educação (PME)}

Em 2009, a Semed aderiu ao Programa Mais Educação (PME), programa do governo federal implantado por meio do Plano de Desenvolvimento da Educação - PDE. O PME propõe a educação com tempos e espaços ampliados, com outras atividades e não "mais do mesmo", conforme afirma Moll (2012, p. 133). “A identidade do Programa Mais Educação é a sua preocupação em ampliar a jornada escolar modificando a rotina da escola [...]”. Assim, o PME vem se expandindo em Santarém. Em 2009, atendia 18 escolas na área urbana do município, tendo o total de 2.412 alunos beneficiados. Em 2014 o número de escolas atendidas saltou para 
215, com 19.596 alunos beneficiados, atingindo 54\% das unidades escolares municipais e 34\% de alunos atendidos. Somente em 2012 houve a ampliação do Programa para as escolas do Campo. As escolas foram definidas pelo MEC, que utilizou como critério, a princípio, o baixo Índice de Desenvolvimento da Educação Básica dessas escolas.

As atividades do Programa são realizadas principalmente por meio de oficinas articuladas de forma a ampliar a carga horária de 7 horas. Em um turno são realizadas as atividades do currículo formal das escolas e no contraturno são desenvolvidas as atividades diversificadas em forma de oficinas e atividades lúdicas ou de orientação de estudo. As escolas podem realizar essas atividades em qualquer espaço disponível na escola, ou fora dela (SANTARÉM, 2014c).

A contratação dos professores, responsáveis pelas atividades pedagógicas das áreas de Português e Matemática, é realizada pela Semed. Os monitores são identificados no bairro ou na comunidade e convidados a colaborar com a escola. Esses profissionais trabalham em regime de colaboração, recebendo apenas um ressarcimento do PME para pagamento de transporte.

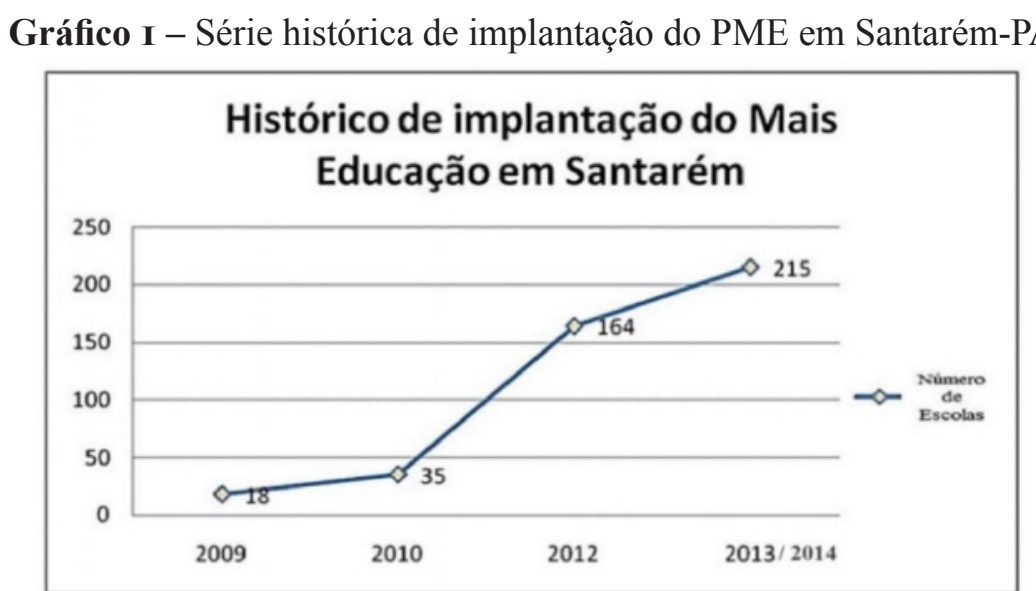

Histórico de implantação do Mais Educação em Santarém

Fonte: Santarém (2014c).

As oficinas temáticas são definidas pelas escolas sem interferência da Semed, baseadas nos macrocampos disponíveis no projeto pedagógico do PME. As atividades mais aceitas pela comunidade escolar, em Santarém, são: teatro, xadrez, ciclismo, canto coral, rádio escolar, arte circense, caratê/capoeira, banda fanfarra, dança, horta escolar/canteiro sustentável (Gráfico 2).

As temáticas das oficinas são possibilidades de ampliação da jornada escolar e diversificação/complementação curricular. As práticas esportivas, de lazer, das artes em geral, objetivam potencializar as habilidades e desenvolver os educandos. Teoricamente, o PME tem esses propósitos, porém, a falta de infraestrutura das escolas, onde as oficinas são realizadas em 
espaços reduzidos, sem qualidade térmica, considerando a região quente e desmatada, a insuficiente formação dos oficineiros, e a desarticulação das oficinas com os projetos pedagógicos das escolas, são condições concretas que desqualificam esse programa na região.

Ainda persiste a fragmentação curricular, as oficinas temáticas são sugeridas por um grupo para outro grupo, pensando por ele e não com ele. A articulação do saber escolar com os saberes da vida traria esse novo significado ao currículo em que o conhecimento, assim como a sociedade, não é estática, mas histórica e isso possibilitaria a desconstrução desse pensamento hegemônico, incluindo elementos da cultura local.

\title{
3.4 A organização curricular e os programas na Semed
}

De acordo com Rocha (2003), o currículo reflete a hegemonia de grupos em determinado contexto histórico-geográfico e sofre as influências da política educacional e da sociedade civil em suas lutas e disputas. Neste texto compreende-se o currículo como sendo os conteúdos ideológicos, pois carregam valores de uma cultura no sentido de estimular resistências ou aceitação do modelo de sociedade existente. Assim, é pertinente refletir sobre o que afirmam Garcia e Moreira:

\begin{abstract}
Dizia-se, por exemplo, que os indígenas não tinham condição sequer de votar, de serem considerados cidadãos. No entanto, sempre produziram tecnologias importantíssimas ligadas à agricultura; durante séculos os indígenas já tinham conhecimentos sobre as qualidades das ervas, sobre como conter a natalidade [...]. O que vem acontecendo, nos últimos anos, e desde muito tempo, é que vem os europeus, os norte-americanos, e agora também os japoneses, [...] para a Amazônia, procuram as populações indígenas, propõem trocas daquilo que os indígenas sabem por [...] migalhas para tapear os índios, que eles veem como ignorantes, embora queiram se apropriar de suas riquezas. Levam, então, esse conhecimento para [...] os grandes centros, patenteiam, transformam em remédios, cremes de beleza, em perfumes, e as multinacionais nos devolvem tudo isso, nos fazendo pagar alto por alguma coisa que saiu daqui. (GARCIA; MOREIRA, 2003, p. 8.).
\end{abstract}

Esse trecho ilustra a relação da comunidade com a escola na produção e na divulgação dos saberes escolares. Não se trata, aqui, de fazer apologia ao senso comum, mas atribuir o devido valor ao que a comunidade produz e como a escola pode articular esses saberes com o currículo escolar, trazendo para a escola os saberes populares. A proposta da educação integral carrega essa possibilidade de romper com a dicotomia entre conhecimento científico e popular; conhecimentos curriculares e extracurriculares. Retomando a discussão de Paviani (2008), defendemos uma proposta curricular que abranja as dimensões ética, estética e epistêmica, ou, 
como prefere Goergen (2005), uma educação que abranja as dimensões corporal, intelectual, afetiva e artística de forma equilibrada, numa perspectiva não hierarquizada. Ou ainda, o resgate da paidéia, discutida por Jaeger (1995), pois aos gregos interessava formar o ser humano completo, com senso crítico e estético na busca pelo equilíbrio da razão e emoção.

Segundo Veiga (2008), os PPP definem a organização do trabalho pedagógico como um todo, envolvendo o plano do que se quer realizar no processo educativo da escola e, também, no processo educativo das escolas e coordenadorias. Ao se fazer levantamento, junto às unidades escolares e/ou setores responsáveis, constatou-se que nem todas possuem PPP, como apresenta o quadro 1.

Quadro I - Número de escolas e coordenadorias que possuem PPP e a situação junto ao CME

\begin{tabular}{|c|c|c|}
\hline Escola/Projetos & Possui PP & Situação junto ao CME \\
\hline Escola da Floresta & Sim & Não enviado ao conselho. \\
\hline Escola do Parque & Sim & Não enviado ao conselho. \\
\hline Escola Irmã Dorothy & Sim & Autorizado. Parecer N $N^{\circ} 33 / 2015$ do CME/STM/PA. \\
\hline Escola Frei Fabiano & Sim & Autorizado. Parecer N ${ }^{\circ} 213 / 2015$ do CME/STM/PA. \\
\hline Escola de Arte & Não & Possui o Plano Anual de Trabalho (PAT). \\
\hline
\end{tabular}

Fonte: Elaborado pelas autoras, com base nos relatórios e Portaria.

Nota: Não há exigência regulamentada pelo CME, para a elaboração do PPP pelas Escolas de Atendimento complementar. O PAT só é exigido pela Divisão de Planejamento da Semed para a Escola de Arte.

O quadro 1 apresenta duas escolas de tempo integral, cujos PPPs foram elaborados e encaminhados ao CME para avaliação, sendo considerados aprovados, o que demonstra, de alguma forma, a autonomia das escolas nesse processo de elaboração conjunta. Por outro lado, as escolas de atendimento complementar possuem apenas um plano de trabalho, pois não há exigência regulamentada pelo CME de apresentação do PPP.

Em relação ao conteúdo dos PPPs, procurou-se verificar as dimensões do conhecimento contempladas. Os projetos estão sustentados em referenciais teóricos progressistas e democráticos, porém, em relação à proposta curricular não se percebe consistência. São textos vagos e com fraca objetividade, o que denota falta de concepções claras sobre o assunto.

A Escola "Irmã Dorothy", identificada como escola do campo, tem como público-alvo, os filhos de agricultores da região. Essa informação de base identitária da escola é fundamental para verificar a pertinência do currículo que pratica. Em relação aos conteúdos trabalhados, o 
projeto se refere a "ampliação do universo cultural partindo da realidade concreta e singular de cada educando" (SANTARÉM, 2015b, p. 14). Em sua proposta, o "currículo é toda experiência que o aluno traz para a escola, bem como as relações vivenciadas, e os conteúdos são partes integrantes do planejamento" (SANTARÉM, 2015b, p. 17). Observou-se o emprego da expressão "relações vivenciadas", quando afirmam que currículo é compreendido como ações e relações no interior da escola. Essas expressões, contidas no PPP da escola, nos remete ao Plano Nacional de Implementação das Diretrizes Curriculares Nacionais para a Educação das Relações Étnico-raciais e para o ensino de História e Cultura Afro-brasileira e Africana em cumprimento às leis no 10.639/2003. Sobre a concretização dessa lei na escola, Nascimento e Mascarenha afirmam que:

educação integral, voltada para a equidade, pressupõe alterações no currículo escolar e exige bem mais do que inclusão de novos conteúdos, mas que se repensem as relações étnico-raciais, sociais, pedagógicas, procedimentos de ensino, formação de professores e condições oferecidas para a aprendizagem. (NASCIMENTO; MASCARENHA, 2015, p.143).

A Lei № 11.645 que inclui os temas referentes à história e cultura e afro-brasileira e dos povos indígenas brasileiros afirma que esses conteúdos serão ministrados no âmbito de todo o currículo escolar, em especial nas áreas de educação artística e de literatura e história brasileira. Entretanto, não se observa, nos PPPs analisados, como serão trabalhados esses conteúdos, fazendo-se menção apenas aos pressupostos teóricos dos mesmos.

Essa escola pratica o currículo pleno, formado pelas disciplinas e programas estabelecidos pelo MEC; e o currículo eletivo, integra as atividades extraclasses, em horário complementar. Tal procedimento aponta certa incoerência entre os pressupostos teóricos, definidos anteriormente, pois uma trajetória inovadora pressupõe práticas diferentes e novo direcionamento às ações educativas. É preciso romper com esse modelo dicotomizado de conteúdos formais e conteúdos diversificados. Pressupõe-se que, o que é pleno, é total, ao passo que se é eletivo, é parcial. A opção política e ideológica se revela ao se eleger tais conteúdos e não outros.

O PPP da Escola "Irmã Dorothy” foi implantado na perspectiva de um currículo escolar organizado em torno de vivências da realidade concreta e singular de seus alunos, porém, distribui sua rotina em um turno fechado com os conteúdos formais propostos pelo MEC (turno de quatro horas) e outro menos denso, com projetos de extensão (duas horas e meia). Tal rotina 
nos leva a pensar que ainda não se articula turno e contraturno na perspectiva de educação integral.

Mesmo assim, os conteúdos comunitários dentro das dimensões do conhecimento se fazem presentes, sendo organizadas três áreas distintas: a ética, que se vê nos projetos ambientais de valorização e sustentação da agricultura familiar; a estética, que se vê nas oficinas de música, teatro, artes; a epistêmica, pelos conteúdos formais das ciências em geral.

A Escola Frei Fabiano Merz apresenta em seu PPP uma concepção de educação transformadora em que o "processo ensino/aprendizagem valoriza a cultura local e as experiências dos sujeitos aprendizes" (SANTARÉM, 2014a, p. 9). Além de promover a “compreensão do ambiente natural e social, da formação de atitudes e valores e dos vínculos familiares e de tolerância" (SANTARÉM, 2014a, p. 10).

Parte do pressuposto de que as relações vivenciadas na escola e os conteúdos trabalhados fazem parte do currículo, cuja concepção ampla abrange todas as atividades, comportamentos, atitudes, formação de valores e outras competências, como o domínio da leitura, a capacidade de realizar cálculos, de analisar e interpretar a realidade, capacidade de viver em grupo.

Assim como a Escola "Irmã Dorothy", também a Escola "Frei Fabiano" pratica o currículo pleno e o eletivo, sendo que este visa à ampliação do currículo pleno. Entretanto, há uma diferença. Enquanto no currículo eletivo da primeira se destaca uma iniciativa de se trabalhar com conteúdos da ética, como as questões ambientais, por exemplo, nesta, os projetos complementares estão pautados nas datas comemorativas da escola, quais sejam: carnaval, páscoa, dia das mães, festa junina, dia dos pais, folclore, semana da criança, natal, embora se perceba certo direcionamento de resgate da cultura local a partir dessas datas, que integram o calendário da escola.

O planejamento da proposta curricular precisa acolher a diversidade trazida para a escola, pelos alunos e familiares, e traduzida em ritmos e formas de aprender. As experiências de ensino e de aprendizagem, na direção dos objetivos traçados, precisam estar afinadas com essa diversidade, numa abordagem política e cultural, segundo Arroyo (1999).

Nos fundamentos teóricos do PPP da Escola "Frei Fabiano" existe um indicativo de organização curricular em direção a uma abordagem sociocultural, porém, não se percebe um direcionamento coerente para operacionalizar essa proposta. Na Escola "Irmã Dorothy", embora não se tenha concretizado um currículo unificado, percebe-se uma preocupação com os temas diversificados, numa tentativa de respeitar a realidade social e cumprir com os objetivos de uma escola do campo. Enquanto na Escola "Frei Fabiano" o foco e o empenho estão na 
episteme, refletida na preocupação com as avaliações externas e locais, com metas bem definidas estatisticamente, conforme verificado no projeto.

$\mathrm{Na}$ Escola da Floresta, enfatiza-se a relação do ser humano e sua responsabilidade com a preservação e conservação de rios, lagos e igarapés, assim como a diversidade de peixes da nossa região. A Escola do Parque dispõe dos seguintes ambientes de atividades em Educação Ambiental: um Viveiro de Quelônios, um Barracão da Diversidade Cultural, um Museu de Resíduos Sólidos, dois Canteiros de Hortaliças, Pomar dos Sabores, uma Casa da Várzea, viveiro de plantas ornamentais, frutíferas e medicinais, trilhas interpretativas. A escola tem uma rotina de atividades diárias aos alunos visitantes com objetivos temáticos de acordo com os espaços visitados.

O tema Meio ambiente insere-se na agenda mundial, ganhando destaque a partir do final do século XX em decorrência dos impactos ambientais. Tem sido cada vez mais urgente encontrar soluções viáveis nessa área, pois o futuro da humanidade depende da relação estabelecida entre a natureza e a forma com a qual o ser humano utiliza seus recursos. Nessa luta por uma sociedade mais saudável, a escola é intimada pela Lei 9.795/1999 que institui a Política Nacional da Educação Ambiental, a apresentar propostas pedagógicas, acrescentando essa temática em seus currículos.

Padilha (2015) reforça os efeitos de um currículo para a educação integral, em que o respeito pelo outro e pelo meio e a perspectiva de emancipação e transformação valorizem a convivência ética e estética, entre os que se beneficiam dessa educação.

No gráfico 2 observamos a variedade de atividades curriculares do PME nas escolas de Santarém e é possível perceber, também, que há uma preferência por alguns temas.

Observa-se um acento maior no tema Agroecologia/Educação ambiental (conteúdo de dimensão ética), na região de rios e na região de planalto (campo), enquanto na cidade o peso maior está na área rítmica e motora (estética), como banda fanfarra, esporte na escola, dança, capoeira, canto coral, karatê, percussão, flauta doce, coral. Tais escolhas refletem que o interesse está diretamente vinculado às práticas culturais locais ou, quem sabe, à vocação de cada espaço geográfico.

As oficinas de orientação de estudos e leitura, e arte gráfica e leitura são obrigatórias no programa, podendo a escola optar por uma das duas. Vemos a possibilidade de, nessas oficinas, articular o conhecimento estético com o epistêmico, o que nos parece salutar, pois as dimensões do conhecimento estão imbricados enquanto potencialidades humanas. 
Gráfico 2 - Macrocampos desenvolvidas nas escolas atendidas pelo PME (2013-2014)

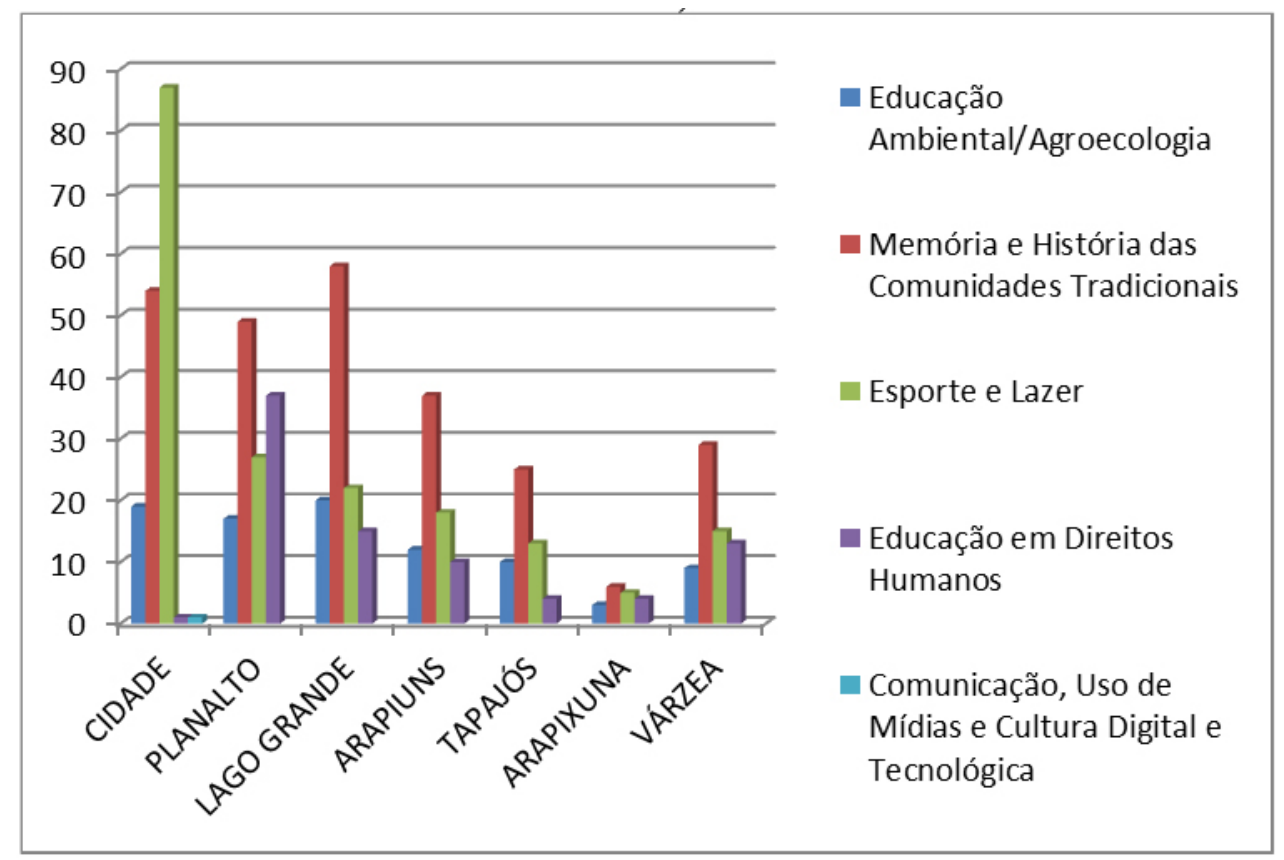

Fonte: Santarém, 2015c

As oficinas têm por finalidade atender as demandas formativas dos alunos em educação de tempo integral, como o desenvolvimento de competências múltiplas: motoras, psicossociais e cognitivas, além da valorização da identidade cultural. Têm, portanto, o caráter de complementariedade curricular de uma parcela significativa da sociedade - as crianças das classes populares e em situação de vulnerabilidade social.

\section{CONSIDERAÇÕES FINAIS}

Abordar o tema da educação de tempo integral, por meio das ações realizadas, pela uma Secretaria Municipal de Educação, exigiu inicialmente a compreensão conceitual, legal e pedagógica, da educação integral e da educação de tempo integral presente nos documentos oficiais da política indutora do Ministério da Educação. Em seguida, o estudo dos documentos da Secretaria Municipal de Educação de Santarém, para que pudessem ser cotejados com as ricas análises já efetuadas por estudiosos da temática. Dadas as limitações de espaço para este artigo, aqui foram apresentadas apenas as linhas gerais que orientem o/a leitor/a na identificação e na interpretação dada sobre as ações da Semed com vistas a implantação da educação de tempo integral, no conjunto das políticas nacionais. 
Partimos da compreensão de que os espaços educativos devem oportunizar o acesso e a apreensão de conhecimentos diversificados, valorizando a imaginação, a afetividade, os esportes e o lazer, sem descuidar do pensamento crítico, a memória, e tudo o que a escola já realiza em termos cognitivos. Educação de tempo integral, como etapa importante da almejada educação integral que envolva dimensões estéticas, éticas, epistemológicas e a formação de pessoas em sua plenitude. Tudo isso requer atenção especial e diferenciada que leve em conta o tempo, o espaço, e os diversos formatos de aprendizagens. E isto não pode se reduzir a ampliação do tempo de permanência do estudante na escola. Mesmo que este tempo seja ocupado com algumas atividades diferenciadas daquelas que a escola comumente realiza.

A quebra de paradigma de uma escola fechada para outra, que vai além de seus muros, demanda novas formas de atuação. Trata-se de ver os responsáveis pela ação educativa como produtores dela e não somente, meros executores. Quando os professores e comunidade estão envolvidos, tornam-se responsáveis pela educação dos alunos e do seu próprio processo de formação. O currículo praticado pela Semed, de um modo geral, se mostrou insuficiente para dar conta da educação integral no município. Deduz-se, da análise dos documentos, uma concepção equivocada de currículo, quando se identifica uma ampliação de conteúdos sem a sua necessária integração. Ainda persiste uma visão reducionista de espaços educativos, de conhecimento, que priorizam os científicos, secundarizando os conteúdos éticos e estéticos.

Os dados revelaram que houve crescimento da oferta de ampliação do tempo escolar no município de Santarém está sendo desenvolvido nas escolas municipais por meio do Programa Mais Educação. Ações importantes e merecedoras de maior atenção como a Escola da Floresta, a Escola do Parque e a Escola de Arte ficaram estagnadas. Os números podem até impressionar, quando verificamos que de 2009 para 2014, subiu de 18 para 215 escolas atendidas pelo Programa Mais Educação, o que aumentou de 2.412 para 19.596 estudantes atendidos. Estatísticas que agradam a um tipo de analista que só consegue ver a realidade na perspectiva quantitativa. Mas os números escondem muitos outros aspectos. Daí a importância de uma leitura criteriosa, crítica, fundamentada em uma perspectiva qualitativa.

\section{Referências}

ARROYO, M. G. Ciclos de desenvolvimento humano e formação de educadores. Educação \& Sociedade, Campinas, v. 20, n. 68, p. 143-162, 1999. Disponível em: <https://goo.gl/ jFHQf3>. Acesso em: 20 out. 2015. 
BRASIL. Lei no 9.795, de 27 de abril de 1999. Dispõe sobre a educação ambiental, institui a Política Nacional de Educação Ambiental e dá outras providências. Diário Oficial [da] República Federativa do Brasil, Brasília, DF, 28 abr. 1999. Disponível em: <https://goo.gl/ vPVKmF>. Acesso em: 6 mar. 2014.

. Lei $\mathrm{n}^{\circ} 11.645$, de 10 de março de 2008. Estabelece as diretrizes e bases da educação nacional, para incluir no currículo oficial da rede de ensino a obrigatoriedade da temática "História e Cultura Afro-Brasileira e Indígena". Diário Oficial da União, Brasília, DF, 11 mar. 2008. Disponível em: < https://goo.gl/PDeX7X>. Acesso em: 9 jun. 2014.

. Ministério de Estado da Educação. Secretaria de Educação Continuada, Alfabetização e Diversidade. Programa Mais Educação: passo a passo. Brasília, 2011. 36 p. (Série Mais Educação).

. Ministério da Educação. Secretaria de Educação Continuada, Alfabetização e Diversidade. Programa Mais Educação: passo a passo. Brasília, 2013a. 48 p. (Série Mais Educação)

. Ministério da Educação. Secretaria de Educação Básica. Diretoria de Currículos e Educação Integral. Manual operacional de educação integral. Brasília, DF, 2013b. p. 1-77. Disponível em: <https://goo.gl/bTsB5t $>$. Acesso em: 13 ago. 2015.

CAVALIERE, A. M. Educação integral: uma nova identidade para a escola brasileira? Educação \& Sociedade, Campinas, v. 23, n. 81, p. 247-270, 2002. Disponível em: <https:// goo.gl/iqd71R $\geq$. Acesso em: 21 mar. 2014.

COELHO, L. M. C. C. História(s) da educação integral. Educação integral e tempo integral. Revista em Aberto, Brasília, v. 22, n. 80, p. 83-96, 2009. Disponível em: <https://goo. gl/7XvNsF>. Acesso em: 3 maio 2014.

GARCIA, R. L.; MOREIRA, A. F. B. (Orgs.). Currículo na contemporaneidade: incertezas e desafios. São Paulo: Cortez, 2003.

GOERGEN, P. Educação e valores no mundo contemporâneo. Educação \& Sociedade, Campinas, v. 26, n. 92, p. 983-1011, 2005. Disponível em: $<$ https://goo.gl/n1MFMs >. Acesso em: 26 jun. 2015.

GRAMSCI, A. Cadernos do Cárcere (I89I-I937). Ed. Trad. Carlos Nelson Coutinho. 2. ed. Rio de Janeiro: Civilização Brasileira, 2001. 2 v.

JAEGER, W. Paideia: a formação do homem grego. São Paulo: Martins Fontes, 1995.

MOLL, J. A agenda da educação integral: compromissos para sua consolidação como política pública. In: . (Org.). Caminhos da educação integral no Brasil: direito a outros tempos e espaços educativos. Porto Alegre: Penso, 2012. p. 129-146.

NASCIMENTO, C. N.; MASCARENHA, P. Educação integral e formação continuada de professores: desafios para implementação da Lei 10.639/03 na rede municipal de ensino do município de Santarém. In: COLARES, M. L. I. S. (Org.). Escola de tempo integral: registros, análise e perspectivas em Santarém/PA. Curitiba: CRV, 2015. p. 143-158. 
PADILHA, P. R. Paulo Freire: educação integral, planejamento e currículo. Boletim UniFreire, São Paulo, 24 nov. 2015. Disponível em: <https://goo.gl/GQxY2f $\geq$. Acesso em: 28 nov. 2015.

PAVIANI, J. Platão \& a educação. Belo Horizonte: Autêntica, 2008.

ROCHA, G. O. R. A pesquisa sobre currículo no Brasil e a história das disciplinas escolares. In: GONÇALVES, L. A. O. (Org.). Currículo e políticas públicas. Belo Horizonte: Autêntica, 2003. p. 41-61.

SANTARÉM. Secretaria de Municipal de Educação. Relatório consolidado 2005-20I2. Santarém, 2012. . Projeto pedagógico da Escola de Ensino Fundamental Frei Fabiano Merz. Santarém, 2014a. . Projeto pedagógico da Escola da Floresta e Escola do Parque. Santarém, 2014b. . Relatório consolidado 2013. Santarém, 2014c. . Censo escolar 2008-20I4. Santarém, 2015a. . Projeto pedagógico da Escola de Ensino Fundamental e Irmã Dorothy Mae Stang. Santarém, $2015 \mathrm{~b}$. . Relatório consolidado 20I4. Santarém, 2015c.

SILVA, R. M. A ecopedagogia fundamentando uma prática curricular. Revista UniFreire, São Paulo, v. 1, n. 1, p. 72-81, 2013. Disponível em: <https://goo.gl/SmXqgQ>. Acesso em: 26 nov. 2015.

TEIXEIRA, A. Centro Educacional Carneiro Ribeiro. Revista Brasileira de Estudos Pedagógicos, Rio de Janeiro, v. 31, n. 73, p. 78-84, jan./mar. 1959.

VEIGA, I. P. A. (Org.). Projeto político-pedagógico da escola: uma construção possível. 24. ed. Campinas: Papirus, 2008. 110 p.

Recebido em: 20/10/2016

Revisado em: 09/12/2017

Aprovado para publicação em: 11/12/2017

Publicado em: 20/12/2017 